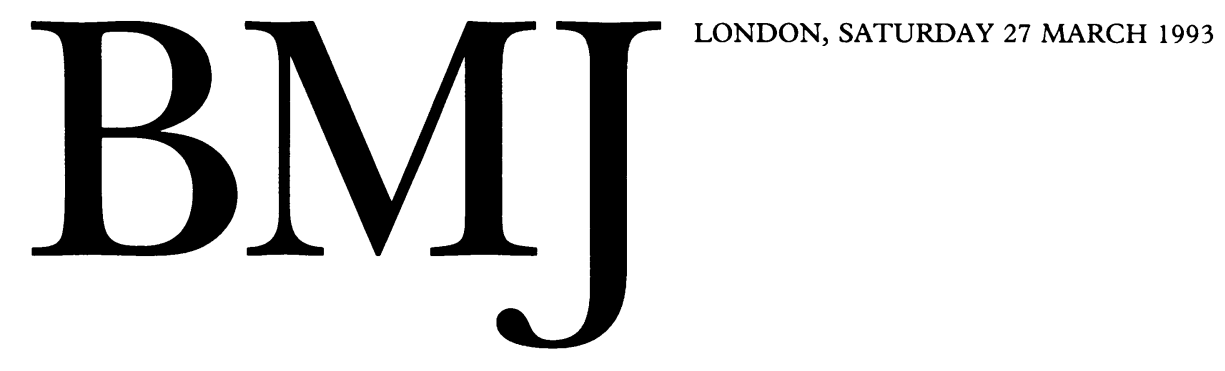

\title{
Thyroid eye disease
}

\author{
Newly described autoantigens and immunoglobulins may hold the key
}

The signs of thyroid eye disease vary greatly from patient to patient. ${ }^{1}$ Not all patients with Graves' disease have eye signs, and, when present, they may be asymmetric. Identical signs may be present in patients with Hashimoto's thyroiditis and, rarely, in euthyroid patients with no obvious disturbance of thyroid function. ${ }^{2}$ Lid retraction and lid lag are usually asymptomatic; more general features, such as severe congestion, often cause local discomfort and excessive tears. Diplopia resulting from the involvement of extraocular muscles may be very disabling.

Generalised oedema in the orbit and periorbital tissues adds to the disfigurement. As the bulk of the intraorbital, extraocular tissues increases the eyeball is progressively pushed forwards, leading to increasingly severe proptosis and possible corneal exposure and ulceration. The resulting corneal opacity used to be one of the main threats to vision. The other was atrophy of the optic nerve after prolonged compression.

Clinical experience suggests that controlling hyperthyroidism usually impedes the development of thyroid eye disease. Some people believe that the choice of antithyroid treatment is important, and all the currently used antithyroid treatments have been blamed for adversely affecting the eye signs. So far the case against any single method of treating hyperthyroidism remains unproved. ${ }^{3}$

Total thyroidectomy was advocated in the 1960s as a means of curing thyroid eye disease but never became generally accepted. Similarly, Britain has few enthusiasts for local irradiation of the orbits. On the hypothesis that thyroid eye disease is, like Graves' disease, an autoimmune disturbance, immunosuppressant drugs have been used with variable and conflicting results.

Very occasionally thyroid eye disease progresses rapidly with increasingly severe signs, including marked exophthalmos, and threatens sight. Such "malignant exophthalmos" can often be reversed, or at least arrested, by the use of a short course of very high doses of prednisolone. Patients should be managed jointly by an endocrinologist and ophthalmologist; if steroids produce no improvement then the orbit may need surgical decompression. Patients whose eye signs are disfiguring or disabling rather than sight threatening should be assessed serially by an ophthalmologist. Only when the eye disease has become stable can corrective surgery for squint be undertaken. Surgical intervention may be indicated in other circumstances-for example, lateral tarsorrhaphy to protect the exposed cornea if lubricating eye drops do not suffice.

Over the past few decades the prevalence of severe eye disease may have fallen with earlier diagnosis and treatment of Graves' disease. Modern management can almost always prevent loss of sight or severe residual disability; most patients regard the end result as reasonably satisfactory.

Nevertheless, thyroid eye disease remains a mystery. No genetic predisposition to the condition has been found, and the only identified risk factor is heavy cigarette smoking. ${ }^{4}$ Disturbed thyroid function in both Graves' disease and Hashimoto's disease results from disturbed immune tolerance. The close association of thyroid eye disease with these disorders and the histological changes in the orbital tissues are certainly compatible with an autoimmune disturbance; on this basis it has been postulated that thyroid eye disease must also be linked in some way with disturbed autoimmunity in the thyroid.

Apart from one report that monoclonal antibodies to the thyrotrophin receptor provoked excessive production of collagen in fibroblast cultures, ${ }^{5}$ there is no evidence that any of the three commonly measured thyroid autoantibodies has a role in the pathogenesis of thyroid eye disease. ${ }^{6}$ Although it has been postulated that immune complexes arising in the thyroid may be conveyed to the orbit by the lymphatics communicating between these two tissues, this is thought unlikely.

On macroscopic examination of the orbit the most striking change is enlarged extraocular muscles. Although the muscle fibres are not obviously abnormal on histological examination, there is usually some lymphocytic infiltration and oedema. Greater changes are seen in the interstitial tissue, which has both diffuse and focal mononuclear cell infiltration containing mostly activated $\mathrm{T}$ cells, some $\mathrm{B}$ cells, macrophages, and mast cells. Interstitial oedema is accompanied by an increased glycosaminoglycan content; less commonly, orbital fat and the lacrimal gland are affected. The result is increased deposition of collagen and fibrosis in extraocular muscles. Weetman has pointed out that these effects could be mediated by cytokines derived from the interaction of $T$ cells, macrophages, and fibroblasts. ${ }^{8}$

To prove that any disease is due to disturbed autoimmunity it is necessary to identify specific antigens. Obtaining orbital tissues for analysis is obviously difficult; 
only small biopsy specimens can be obtained, and only in special circumstances. Tissue obtained at surgery to correct residual squint after the thyroid eye disease is quiescent is unlikely to further our understanding of the acute phase of the disease. The same problems apply to tissue obtained at necropsy from patients with a history of thyroid eye disease.

Considerable efforts have been made to identify specific interactions between the immunoglobulins of patients with thyroid eye disease and orbital muscle membranes usually of porcine origin. Even in studies on human eye muscle membranes the results have not been consistent, probably because of methodological problems. ${ }^{9}$ Immunoblotting, a cruder technique for identifying antigens, has recently shown that a $64 \mathrm{kd}$ protein might be an autoantigen related to thyroid eye disease, ${ }^{10}$ and this protein has been cloned and sequenced."

Perros and Kendall-Taylor have recently shown that immunoglobulins that bind to porcine eye muscle membranes increase the growth of a monoclonal porcine myoblast culture. ${ }^{12}$ This is the first report of a direct effect of immunoglobulins from patients with thyroid eye disease on an orbital tissue, and the work needs repeating with myoblasts from human extraocular muscles.

At this stage the question of whether thyroid eye disease results from autoimmune disturbance remains open. The best hopes of furthering our understanding must lie with work on the functional role of the recently sequenced $64 \mathrm{kd}$ protein in orbital muscle and on the growth promoting properties of the ophthalmopathic immunoglobulins described by Perros and Kendall-Taylor.

DONALD MUNRO

Emeritus professor of medicine

Department of Human Metabolism and Clinical Biochemistry,

University of Sheffield,

Sheffield F10 2RX

1 Marcocci C, Bartalina L, Bogaggi F, Paricucci M, Pinchera A. Studies on the occurrence of ophthalmopathy in Graves' disease. Acta Endocrinol 1989;120:473-8.

2 Solomon DH, Chopra IJ, Chopra U, Smith FV. Identification of subgroups of euthyroid Graves' ophthalmopathy. N Engl Y Med 1977;296:181-6.

3 Feldon SE. Graves' ophthalmology. Is it really thyroid disease? Arch Intern Med 1990;150: 948-50.

4 Shine B, Fells P, Edwards OH, Weetman AP. Association of Graves' ophthalmopathy and smoking. Lancet 1990;335:1261-3.

5 Rotella CM, Zonefrati R, Toccafondi R, Valente WA, Kohn LD. Ability of monoclonal antibodies to the thyrotrophin receptor to increase collagen synthesis in human fibroblasts; an assay which appears to measure exophthalmogenic immunoglobulins in Graves' sera. 7 Clin Endocrinol Metab 1986;62:357-67.

6 Bech K. Thyroid antibodies in endocrine ophthalmopathy. A review. Acta Endocrinol 1989;121 (suppl 2):117-22.

Kriss JP. Radioisotopic thyroidolymphography in patients with Graves' disease. 9 Clin Endocrinol Metab 1970;31:315-24.

8 Weetman AP. Thyroid associated eye disease: pathophysiology. Lancet 1991;338:25-8.

9 Weetman AP. Thyroid associated ophthalmopathy. Autoimmunity 1992;12:215-22.

10 Salvi M, Hiromatsu Y, Bernard N, How J, Wall JR. Human orbital tissue and thyroid membrane express a $64 \mathrm{KDa}$ ' protein which is recognised by autoantibodies in serum of patients with thyroid associated ophthalmopathy. FEBS Lett 1988;232:135-9.

11 Dong O, Ludgate $M$, Vasart G. Cloning and sequencing of a novel $64 \mathrm{kd}$ autoantigen recognised by patients with autoimmune thyroid disease. F Clin Endocrinol Metab 1991;72:1375-81.

12 Perros P, Kendall-Taylor P. Biological activity of autoantibodies from patients with thyroid associated ophthalmopathy: in vitro effects on porcine extraocular myoblasts. $Q \mathcal{J}$ Med 1992;84:691-706.

\section{Institutional care and elderly people}

\section{What do the changing patterns mean?}

One of the aims of Britain's health and social services for the past 40 years has been to help old people to live in their own homes. Although innovative schemes have made it possible to maintain at home people with disabilities that were once thought to require hospital or residential care, ${ }^{1}$ it is unrealistic to suggest that institutional care could be entirely dispensed with. For patients with low levels of dependency, providing domiciliary care is cheaper than providing institutional care, but at high levels of dependency it becomes more expensive. At some level of expenditure it presumably becomes inequitable for a disabled person to expect public support for the more expensive domiciliary care if this means depriving someone else of care of any sort.

Further problems identified by Kellett in this week's journal $(p 846)^{2}$ centre on the inequity and illogicality of NHS care being free while care under the rubric of the community, even if provided in an institution, carries a means tested price tag. There seems nothing in the present arrangements to prevent two similarly disabled old people being in adjacent rooms in a nursing home, one of whom has her lifetime earnings bled down by "community care" while the family of the other looks forward to an undiminished inheritance courtesy of the NHS.

Be that as it may, the potential advantages of long term care in a high quality private sector are considerable, particularly as this sector offers old people and their families wider choice than the public sector. Autonomous nursing units may be able to offer their residents more adaptable care when they are free from the rigid timetables inseparable from hospital organisation.

Under experimental conditions, old people in NHS nursing homes may do at least as well as those in traditional geriatric wards, ${ }^{34}$ but the same cannot be assumed of units removed from the traditions and surveillance of a health or social services hierarchy. American experience provides grounds for anxiety over the welfare of old people in an inadequately monitored private sector.

Two further concerns have been generated by the massive growth in the number of private residential and nursing homes following changes in social security regulations in the past decade. First is the possibility of an unnecessary increase in the number of old people consigned to institutional care. ${ }^{5}$ Secondly, the private sector may have been "creaming off" clients with low dependency, who yield high profit margins, leaving the public sector to cope with more demanding patients without appropriate improvements in staffing and facilities.

In this week's journal Stern and colleagues report on two censuses carried out in 1979 and 1990 of elderly people in residential care in Leicestershire (p 827). ${ }^{6}$ During the 11 years the numbers of residents in NHS geriatric and psychiatric beds fell by $41 \%$; this fall was partly compensated for by a $37 \%$ rise in the number of patients in acute beds. On the assumption that this transfer represents better access of elderly people to the best of modern medicine and surgery, it must be a good thing. In contrast, the number of people in private sector homes almost quadrupled. The total number of people aged 65 and over in institutions increased by $30 \%$ between the two censuses, but because of population growth this represents an increase in proportion of only $0.5 \%$, from $4 \cdot 2 \%$ to $4 \cdot 7 \%$. Furthermore, this increase is entirely explained by the aging of the population between the two censuses.

These findings do not confirm fears of an overall increase in the number of old people looked after in institutions, and 